\title{
Bayesian Modeling of a Wind Turbine System in the Preliminary Design Phase
}

\author{
Souad Nabdi ${ }^{1}$, Hamid Zaghar ${ }^{2}$ and Brahim Herrou ${ }^{3}$ \\ ${ }^{1}$ Laboratory of industrial techniques, faculty of sciences and techniques of Fez, University Sidi Mohamed Ben Abdellah, Fez, Morocco. \\ ${ }^{2}$ Superior School of Technology, University Sidi Mohamed Ben Abdellah, BP. 2427 Imouzzer road, Fez. \\ ${ }^{3}$ Laboratory of industrial techniques, Higher School of Technology, University Sidi Mohamed Ben Abdellah, BP. 2427 Imouzzer road, \\ Fez.
}

Received 11 March 2017; Accepted 11 September 2017

\begin{abstract}
Of our days, the question of industrial competitiveness is of particular importance for the industries in all sectors of activity. The next years will be marked by persistent pressures on the cost and the quality of the systems. Of this fact, an analysis of the safety of operation constitutes a necessary approach for the improvement of the operation of the systems by acting as soon as the primary phases of the design on the settings and the factors influencing the functioning of these systems. In effect, the modeling is a critical phase in this kind of analysis and the literature presents several tools enabling this modeling. In operational safety, there is often little information available. It is therefore generally impossible to obtain the parameters describing the Act attached. That is why; modeling tools rely primarily on the judgment of experts, surveys and databases of the manufacturers to build models structured. In this perspective, the Bayesian networks are a powerful solution of modeling for complex systems to merge the knowledge of various natures within a same model. In this logic, we will present a modeling by Bayesian networks of the two concepts of turbine namely direct and indirect in the aim of constructing a decision of choice between the two concepts in the preliminary phase of design of wind turbines while presenting the method, the calculation of the probability of state and the validation criteria of choice.
\end{abstract}

Keywords: modeling, Bayesian networks, preliminary design, wind turbine system

\section{Introduction}

The uncertainty is a problem commonly encountered in realworld applications. It can be described as an insufficient amount of information. Nevertheless, the uncertainty may also exist in situations which have a sufficient amount of information. In addition, the uncertainty may be reduced or abolished by the addition of new information. Adding more information in complex processes can lead to the mining limited knowledge. The uncertainty can be calculated mathematically with the theory of probabilities. In uncertain situations, there is an involvement of the possibility of states of attributes. Therefore, the models established on probabilistic inferences have the ability to assign a value probabilistic according to a principle defined.

Accordingly, the prediction with a large number of states in a model is complex. The question which arises is "how the forecast is carried out in the presence of a large number of States in a model?" a response to this question is the employment of the Bayesian network $(\mathrm{BN})$ with several variables [1]. Bayesian networks also known as networks of

Belief, belong to the family in probabilistic graphical models. These structures graphs correspond to the knowledge about a domain uncertain. More specifically, each node in the graphical structure represents a random variable, while the edges / arcs between the nodes represent conditional dependencies between the nodes. These conditional dependencies are estimated using statistical

\footnotetext{
*E-mail address: nabdisouad@gmail.com

ISSN: 1791-2377 @ 2017 Eastern Macedonia and Thrace Institute of Technology. All rights reserved. doi:10.25103/jestr.104.22
}

methods and recognized it.

The application of the $\mathrm{BN}$ on reliability is a relatively recent development, their popularity has grown up in the field of reliability analyzes of the systems since the end of the years 90 [2], [3].A set of 200 articles of applications of BN in Reliability are referenced in an article of synthesis of Weber and al [4]. This article illustrates the interest in the modeling by $\mathrm{BN}$ in the field of the Reliability modeling, of the analysis of the risks and the maintenance during these last ten years and gives a synthesis of scientific locks remaining to resolve.

The salient articles identified in this synthesis are attached to demonstrate equivalency with the methods of probabilistic assessments classically used in Reliability. We find in the work of Torres Toledano [2] an analysis of the benefits of $\mathrm{BN}$ by report to the formalism of reliability diagrams (DF). The work of Bobbio [5], [6] Explain how a tree of failure can be modelled by a BN. The work of Boudali [7], [8] Describe the representation of trees of dynamic failures by Bayesian Networks Dynamic. Finally, [9]-[11] also explain how the DBN can be used to extend the modeling techniques of the reliability of the systems by Markov Chains. These articles present in the literature had for objective to demonstrate the equivalence of the $\mathrm{BN}$ with conventional tools however they have not always develop the many benefits of BN.

In parallel to these articles that are focused on the comparison of methods, new methods of modeling using the real capacities of modeling of $\mathrm{BN}$ have emerged. One of the first articles [12] proposes a methodology exploiting the modeling by $\mathrm{BN}$ in the framework of the evaluation of the reliability of an infrastructure. The publication of Bensi et al 
in 2013 [13] offers a method of construction of the structure of the Model BN is defined in function of minimum links or minimum slices, for the modeling of the performance of the systems multi-states. This article shows a few real interests in the use of in safety in operation compared to the methods of conventional modeling.

Today we have at our disposal a number of articles of synthesis [4], [14]-[16] which give a good view of the maturity of the applicability of the RB to the reliability in the broad sense. The Institute of the control of risks (IMdR) has supported several projects to promote the modeling by $\mathrm{BN}$ : The IMdR project P04-7 has helped to evaluate the relevance of the modeling approach by $\mathrm{BN}$ in relation to the problems of operational safety posed by industrial companies. Unfortunately, this formalism of modeling is not yet fully accepted in the industrial workplace. This lack of acceptance comes from the fact the relative newness of the tool, the possible lack of legibility at the model level, the strong power of modeling that it must dominate and the connotation of the word "Bayesian" in the spirit of a specialist of reliability.

Bayesian Networks can provide effective support in security modeling. Indeed, they have a powerful modeling and analysis power. They provide a formal framework for manipulating or processing probabilistic events into representatives by discrete random variables, as well as the relationships that bind them to the representatives by conditional probabilities. The modeling by this method is appreciated to be based on a powerful formalism of expression of the dependencies and complex independences between random variables. This formalism is therefore well adapted to the representation and study of complex systems. Of this fact, completely define the Bayesian networks therefore requires in the first place to introduce the concepts of graph theory on the one hand and concepts of probabilistic the other part. In addition, understanding where the Bayesian networks come involves doing return first on the question of the treatment of uncertainty.

In this context, the present work is as the first party to introduce the Bayesian networks with a quick overview on the work presented in the literature as well the areas of application. Then we will present this method as modeling tools for the analysis of wind turbines direct and indirect.

\section{Tools and Methods}

\subsection{History and Definitions \\ 2.1.1. Bayesian approach}

The term "Bayesian" refers to Thomas Bayes and is supposed to be put in place for the first time in the 1950s. A Generalized Version of the Bayes theorem was demonstrated independently by Pierre-Simon and marquis Laplace transform. As well, the Bayesian networks (BN) have been presented in [17] In the emphasis on three concepts. The first two concerning the subjective nature of the input information and the second on the update of the information. The last stroke is the distinction between the connection mode and the evidence which has been taken into account by Thomas Bayes mentioned in [18], [19]. Later in [18], the authors have put the point on the benefits of BN as a field of learning. Therefore, we can note several fields of research that uses the $\mathrm{BN}$ such that the treatment of the image, decision-making, the analysis of the operational security of systems, the medicine and the analysis of data, and other areas of additional knowledge.
Bayesian networks rely on a theorem: The Bayes theorem. This is a result of basic theory of probabilities, resulting from the work of the Reverend Thomas Bayes (1702-1761), presented posthumously in 1763. This theorem defines the probabilities as follows: [20]

$\mathrm{P}(\mathrm{A} \backslash \mathrm{B}) \mathrm{P}(\mathrm{B})=\mathrm{P}(\mathrm{A} \cap \mathrm{B})=\mathrm{P}(\mathrm{B} \backslash \mathrm{A}) \mathrm{P}(\mathrm{A})$

$P(A \backslash B)=\frac{P(B \backslash A) P(A)}{P(B)}$

With:

- $\mathrm{P}(\mathrm{A})$ : The a priori probability of $\mathrm{A}$ or the probability of marginal has, it is said "previous", in the sense that it precedes any information on $B$

- $P(A \backslash B)$ : The probability a posteriori knowing $B$, it depends directly on B. It is also called the likelihood function of $\mathrm{A}$

- $\mathrm{P}(\mathrm{B})$ : The a priori probability of $\mathrm{B}$ or the probability marginal of $\mathrm{B}$

Bayesian networks have emerged in the first half of the 1980s and in artificial intelligence. More specifically, they have been introduced in this field as tools of treatment of uncertainty. They are the couples composed of a directed graph acyclic and a distribution of probabilities, defined on the same set of variables, and who have a certain relationship.[20]

A Bayesian network is a system representing the knowledge and allowing calculating conditional probabilities for solutions to different kinds of problems. [21]

The strength of the modeling by BN lies in its capacity of calculation. A BN allows to calculating the marginal distribution of each variable in a function of:

- The observation of the known variables or the likelihood on the state of these variables

- The a priori knowledge of the laws of probabilities of the variables not observed

- Laws of conditional probabilities between the variables.

Depending on the type of application, the practical use of a Bayesian network may be considered in the same way as that of other models [22]: network of neurons, expert system, decision tree, model of data analysis, shaft failures, and logic model. Naturally, the choice of the method involves different criteria, such as the ease, cost and the time limit for the implementation of a solution.

\subsection{Study and modeling of a wind turbine system by a Bayesian approach \\ 2.2.1. Definition of variables}

The variables of states xi of a component of a system of variable $\mathrm{y}$ are defined as:

- The Component I is in operation for $\mathrm{xi}=0$

- The Component I is in a state of Defect operation for xi $=\{1, \ldots .,(\mathrm{Li}-1)\}$

- The Component $\mathrm{I}$ is in fault state for $\mathrm{xi}=\{\mathrm{Li}, \ldots \ldots, \mathrm{ni}\}$

- The system in a state of operation for $y=0$

- The system in a state of Defect operation for $y=\{1, \ldots \ldots$, (1-1)\}

- The system in a state of malfunction for $y=\{L, \ldots ., n\}$ 
With:

$\{1 \ldots(\mathrm{Li}-1)\}$ : shape the operating states of the degraded of the component $\{\mathrm{Li} \ldots \mathrm{Ni})$ : Shape the states of failure of the components that led to a failure of the system.

Such a system is very difficult to submit by a shaft of failure or by a conventional method known in the safety analysis. However, the concepts of minimum slices and paths of minimum success allow you to define fully the relations between the states of the system and the states of the components of where the interest of a structuring in Bayesian network.

2.2.2. The modeling of scenarios of operation of a wind turbine by a Bayesian network

A wind turbine has a role to convert the kinetic energy of wind into electrical energy. Its different elements are designed to maximize this energy conversion and, in general, a good match between the torque characteristic/speed of the turbine and the generator energetic is indispensable. To achieve this objective, ideally, a wind turbine must include:

- A system that allows the check mechanically namely: system of orientation of the pale, and orientation of the Nacelle

- A system that allows the electrically check namely: Electrical machine associated with the control electronics (A converter and a generator)

\subsubsection{The case of an indirect wind turbine}

In this type of turbine, the turbine rotation speed is relatively low, and mechanical torque is high on the output shaft of the turbine. The electrical machines are sized in torque, and it seeks to make them turn quickly to achieve mass powers satisfactory.

That is why it interleaves a mechanical multiplier to gears between the turbine and the generator; this last is often a machine asynchronous to cage or then a machine to dual power supply for a variable speed operation economic. [23]

The presentation of a wind turbine indirect is as follows:

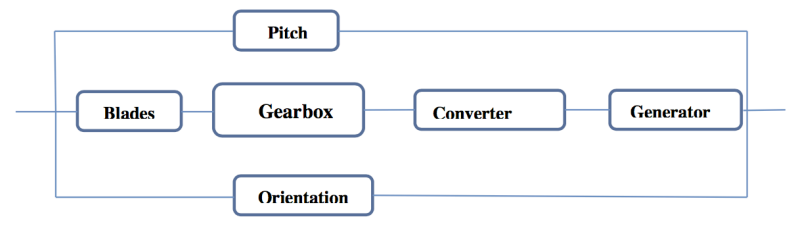

Fig. 1. Representation of an indirect wind turbine

\subsubsection{The case of a direct wind turbine}

The principle of the direct attack consists to couple the generator directly on the propeller. This last operates at low speed of the rotor, which allows you to delete the multiplier, which is the seat of power loss and source of noise. This type of generator must turn speeds between 18 and $15 \mathrm{rpm}$. to produce electricity with this type of machine, it must be that the generator has a large number of poles to obtain a frequency of the order of $50 \mathrm{~Hz}$. [24]

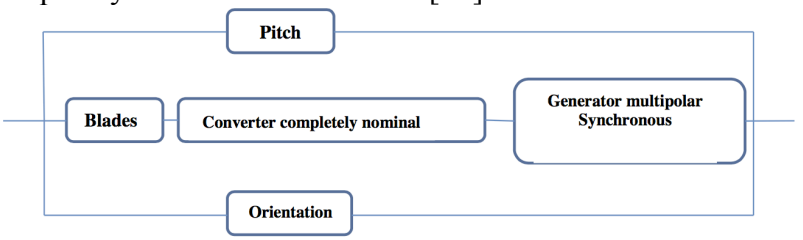

Fig. 2. Representation of direct wind turbine

\subsubsection{The Bayesian network failure scenarios}

Either the variables of the following state:

- Indirect wind turbine : $\mathrm{x} 1, \mathrm{x} 2, \mathrm{x} 3, \mathrm{x} 4, \mathrm{x} 5, \mathrm{x} 6$ : The variables of state respectively of the Pitch, Blades, multiplier, converter, generator and the orientation

- Direct wind turbine : $\mathrm{x} 1, \mathrm{x} 2, \mathrm{x} 3, \mathrm{x} 4, \mathrm{x} 5$ : The variables of state respectively of the Pitch, Blades, converter totally nominal, synchronous generator multipolar and the orientation

-

- $\mathrm{Xi}=0$ : The component is in the normal operating state

- $\mathrm{Xi}=1$ : The component is in a degraded State

- $\mathrm{Xi}=2$ : The component is in the fault state

The three states of the system are defined as follows:

- $\quad 0 ":$ a normal operating state

- "1": a degraded state

- "2": a fault status

For the state of the operation of the system i.e. $(y=0$ and $\mathrm{y}=1$ ), there is four scenarios $\mathrm{Li}$ as follows:

For the indirect wind turbine:

- $\mathrm{L} 1=\{\mathrm{xi}=0\}$

- $\mathrm{L} 2=\{\mathrm{x} 1=2, \mathrm{x} 2,3,4,5=0, \mathrm{x} 6=0\}$

- $\mathrm{L} 3=\{\mathrm{x} 1=2, \mathrm{x} 2,3,4,5=0, \mathrm{x} 6=2\}$

- $\mathrm{L} 4=\{\mathrm{x} 1=0, \mathrm{x} 2,3,4,5=0, \mathrm{x} 6=2\}$

For the direct wind turbine:

- $\mathrm{L} 1=\{\mathrm{xi}=0\}$

- $\mathrm{L} 2=\{\mathrm{x} 1=2, \mathrm{x} 2,3,4=0, \mathrm{x} 5=0\}$

- $\mathrm{L} 3=\{\mathrm{x} 1=2, \mathrm{x} 2,3,4=0, \mathrm{x} 5=2\}$

- $\mathrm{L} 4=\{\mathrm{x} 1=0, \mathrm{x} 2,3,4=0, \mathrm{x} 5=2\}$

The Bayesian network by the minimum links is as follows, with $\mathrm{X}_{2,3,4,5} \sim \mathrm{X}_{\text {unit }}$ in the case of an indirect wind turbine, and $\mathrm{x}_{2,3,4} \sim \mathrm{X}_{\mathrm{unit}}$ in the case of a direct wind turbine:

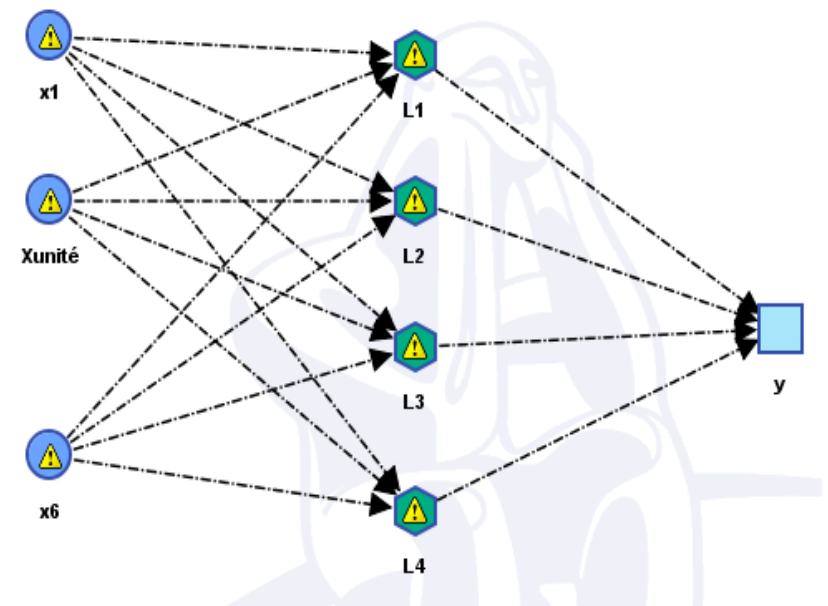

Fig. 3. Functioning Bayesian network of a wind turbine indirect/ direct

2.3. Probability calculation of state for the wind turbine indirect /direct

2.3.1. Data to priori and probability calculation a posteriori for the two types of wind turbine

Our study is based on EU surveys on the rate of failures and repairs in a wind park containing direct wind turbines and indirect wind turbines. [25]-[28] 
Table 1. Collects the data collected as follows:

Table 1. The rates of failures and repairs of systems considered.

\begin{tabular}{|c|c|c|c|c|}
\hline & \multicolumn{2}{|c|}{ Vestas 39/500 } & \multicolumn{2}{|c|}{ Enercon E40 } \\
\hline & $\frac{\mathbf{\mathbf { n }}_{\mathrm{v}}}{\text { (Failure/year) }}$ & $\begin{array}{c}\boldsymbol{\mu}_{\mathrm{v}} \\
\text { (repair/year) }\end{array}$ & $\begin{array}{c}\overline{\boldsymbol{z}}_{\mathrm{E}} \\
\text { (Failure/year) }\end{array}$ & $\begin{array}{c}\boldsymbol{\mu}_{\mathrm{E}} \\
\text { (repair/year) }\end{array}$ \\
\hline The Blades & 0.162 & 265.3 & 0.24 & 135 \\
\hline Gearbox & 0.168 & 269.2 & -- & -- \\
\hline Generator & 0.085 & 170.7 & 0.354 & 143.7 \\
\hline Converter & 0.254 & 508.1 & 0.317 & 430,7 \\
\hline Pitch & 0.095 & 559.9 & 0,292 & 512 \\
\hline Orientation & 0.097 & 436.7 & 0.116 & 348.3 \\
\hline
\end{tabular}

Table 2. Technical specifications of the systems considered

\begin{tabular}{l|c|c}
\cline { 2 - 3 } & Vestas V39/500 & Enercon E40 \\
\hline Technology & Indirect & Direct \\
Power (KW) & 500 & 500 \\
Rotor diameter (m) & 39 & 40 \\
Rotation speed (rpm) & 30 & 12 to 34 \\
Technology to control & Pitch active stall & Pitch variable speed \\
The Turbines considered & 804 & 900 \\
\hline
\end{tabular}

The calculation of the probability of state of the system and its components for the two concepts based on the Bayes theorem is as follows:

$P($ System in a state of running $\backslash$ pitch in failure $)=$ $=\frac{\mathrm{P}(\text { pitch in failurelsystem running }) \mathrm{P}(\text { system running })}{P(P i t c h \text { in }}$ $P($ Pitch in failure $)$
According to the operating scenarios presented above, we have the two scenarios L2 and L3, which will be considered in the calculation of this probability; these two situations represent the degraded state of the system:

$$
\begin{aligned}
& \mathrm{L} 2=\left\{\mathrm{x}_{1}=2, \mathrm{x}_{2,3,4,5}=0, \mathrm{x}_{6}=0\right\} \\
& \mathrm{L} 3=\left\{\mathrm{x}_{1}=2, \mathrm{x}_{2,3,4,5}=0, \mathrm{x}_{6}=2\right\}
\end{aligned}
$$

Of this fact, we can calculate all the probabilities of conditional state of the system and components in operators from the data in Table 1.

With:

- $\mathrm{P}$ ( running $)=e^{-\lambda t}$

- $\mathrm{P}($ in failure $)=\frac{\lambda}{\lambda+\mu}$

- $\lambda$ : rate of failure of the component

- $\mu$ : rate of repair of the component

\section{Results and Discussion}

3.1. Calculation of probability of states of components

Below we present the results of the calculation of probability to $\mathrm{t}=1$ year and to $\mathrm{t}=10$ years in Table 3 and 4 as follows:

\begin{tabular}{|c|c|c|c|c|c|c|c|}
\hline & \multicolumn{2}{|c|}{ Vestas 39/500 } & \multirow[b]{2}{*}{ Unavailability } & \multirow[b]{2}{*}{$R_{v}(t) t=1$ year } & \multirow[b]{2}{*}{$R_{v}(t) t=10$ years } & \multirow[b]{2}{*}{$M_{v}(t) t=1$ year } & \multirow[b]{2}{*}{$M_{v}(t) t=10$ years } \\
\hline & $\begin{array}{c}\boldsymbol{\lambda}_{\mathrm{v}} \\
\text { (Failure/ year) }\end{array}$ & $\begin{array}{c}\boldsymbol{\mu}_{\mathrm{v}} \\
\text { (repair/ year) }\end{array}$ & & & & & \\
\hline The Blades & 0.162 & 265.3 & 0,000610 & 0,850 & 0.198 & 0.150 & 0.802 \\
\hline Gearbox & 0.168 & 269.2 & 0,000624 & 0.845 & 0.186 & 0.155 & 0,814 \\
\hline Generator & 0.085 & 170.7 & 0,000498 & 0.918 & 0.427 & 0.081 & 0,573 \\
\hline Converter & 0.254 & 508.1 & 0,000500 & 0.775 & 0.079 & 0,224 & 0,921 \\
\hline Pitch & 0.095 & 559.9 & 0,000170 & 0.909 & 0,387 & 0.091 & 0.613 \\
\hline Orientation & 0.097 & 436.7 & 0,000222 & 0.907 & 0,379 & 0.092 & 0.621 \\
\hline
\end{tabular}

Table 3. Calculation of probability of functioning and of failure of system components Vestas 39/500

Table 4. Calculation of probability of functioning and of failure of system components Enercon E40

\begin{tabular}{|l|c|c|c|c|c|c|c|}
\hline & \multicolumn{2}{|c|}{ Enercon E40 } & Unavailability & $R_{\mathrm{E}}(\mathrm{t}) \mathrm{t}=1$ year & $\mathrm{R}_{\mathrm{E}}(\mathrm{t}) \mathrm{t}=10$ years & $\mathrm{M}_{\mathrm{E}}(\mathrm{t}) \mathrm{t}=1$ year & $\mathrm{M}_{\mathrm{E}}(\mathrm{t}) \mathrm{t}=10$ years \\
\cline { 2 - 8 } & $\boldsymbol{\lambda}_{\mathrm{E}}$ (Failure/ year) & $\boldsymbol{\mu}_{\mathrm{E}}$ (repair/ year) & & & & & \\
\hline The Blades & 0.24 & 135 & 0,569562 & 0,786 & 0.091 & 0.213 & 0.909 \\
Gearbox & -- & -- & -- & - & - & - \\
Generator & 0.354 & 143.7 & 0,839875 & 0.701 & 0.029 & 0.298 & 0.971 \\
Converter & 0.317 & 430,7 & 0,260135 & 0.728 & 0.042 & 0.272 & 0,958 \\
Pitch & 0,292 & 512 & 0,810152 & 0.746 & 0.054 & 0.253 & 0.946 \\
Orientation & 0.116 & 348.3 & 0,803947 & 0,890 & 0.313 & 0.110 & 0.687 \\
\hline
\end{tabular}

\subsection{Calculation of conditional probabilities}

The table 5 presents the table of conditional probability of the system knowing the probability of state of the components in taking into account the representation of the Bayesian network of the figure 3 and the different scenarios.

\subsection{Discussion of Results}

The purpose of our study is to apply the Bayesian approach on a wind turbine system for the purpose of determining the States of the system and the calculation of conditional probability in order to help designers to make the choice between the two concepts.

As an interpretation of the different results, we will present the findings as follows:

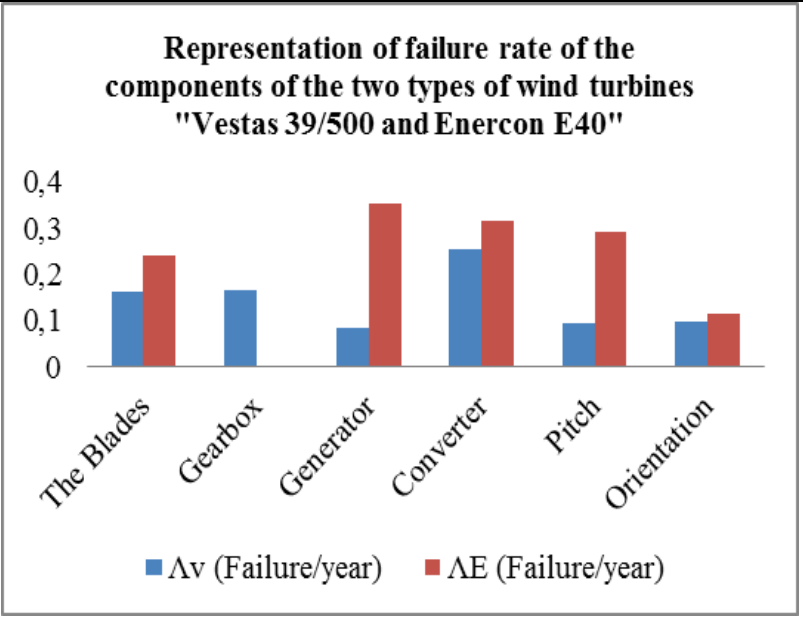

Fig. 4. Representation of failure rates of the components of the two systems considered 
Table 5. Table on the conditional probability of the two systems considered

\begin{tabular}{|c|c|c|}
\hline \multicolumn{2}{|l|}{ Node } & \multirow{2}{*}{$\begin{array}{l}\text { Parameters } \\
Y=0\end{array}$} \\
\hline$X_{i}, L_{i}$ & Parents & \\
\hline$X_{i}$ & --- & $P_{l}=(X i=0)$ \\
\hline$L_{l}$ & $X_{i}$ & $P_{L 1}=(y=0 \backslash X i=0)$ \\
\hline & & $Y=1$ \\
\hline$X_{\text {unit }}$ & --- & $P_{2}=\left(x_{\text {unit }}=1\right)$ \\
\hline$L_{2}$ & $X_{I}, x_{\text {unit }}, x_{6}$ & $P_{L 2}=\left(y=1 \mid x 1=2, x_{u n i t}=0, x 6=0\right)$ \\
\hline$L_{3}$ & $X_{1}, x_{\text {unit }}, x_{6}$ & $\begin{array}{l}P_{L 3}=(y=1 \backslash x 1=2, x \text { unité }=0, \\
x 6=2)\end{array}$ \\
\hline$L_{4}$ & $X_{1}, x_{\text {unit }}, x_{6}$ & $\begin{array}{l}P_{L 4}=(y=1 \backslash x I=0, x u n i t e ́=0, \\
x 6=2)\end{array}$ \\
\hline & & $Y=2$ \\
\hline$X_{\text {unit }}$ & --- & $P_{3}=\left(x_{u n i t}=2\right)$ \\
\hline$L_{5}$ & $X_{1}, x_{\text {unit }}, x_{6}$ & $P_{L 5}=\left(y=2 \mid x_{1}=2, x_{\text {unit }}=2, x_{6}=0\right)$ \\
\hline$L_{6}$ & $X_{1}, x_{\text {unit }}, x_{6}$ & $P_{L 6}=\left(y=2 \backslash x_{1}=2, x_{\text {unit }}=2, x_{6}=2\right)$ \\
\hline$L_{7}$ & $X_{1}, x_{\text {unit }}, x_{6}$ & $P_{L 7}=\left(y=2 \mid x_{1}=0, x_{\text {unit }}=2, x_{6}=2\right)$ \\
\hline$L_{8}$ & $X_{1}, x_{\text {unit }}, x_{6}$ & $P_{L 8}=\left(y=2 \mid x_{1}=0, x_{\text {unit }}=2, x 6=0\right)$ \\
\hline
\end{tabular}

Table 6. Table of probability of the two systems considered

\begin{tabular}{|c|c|c|c|c|c|c|}
\hline & $\begin{array}{l}\text { Psys } \\
\text { walk } \\
t=1 \\
\text { year }\end{array}$ & $\begin{array}{l}\text { Psys } \\
\text { in } \\
\text { failure } \\
t=1 \\
\text { year }\end{array}$ & $\begin{array}{l}\text { Psys } \\
\text { defect } \\
t=1 \\
\text { years }\end{array}$ & $\begin{array}{l}\text { Psys walk } \\
t=10 \\
\text { years }\end{array}$ & $\begin{array}{l}\text { Psys } \\
\text { in } \\
\text { failure } \\
t=10 \\
\text { years }\end{array}$ & 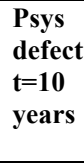 \\
\hline $\begin{array}{l}\text { Vestas } \\
39 / 500\end{array}$ & 0.95 & 0.044 & 0.006 & 0.62 & 0.341 & 0.039 \\
\hline $\begin{array}{l}\text { Enercon } \\
\text { E40 }\end{array}$ & 0.98 & 0.019 & 0.001 & 0.35 & 0.53 & 0.12 \\
\hline
\end{tabular}

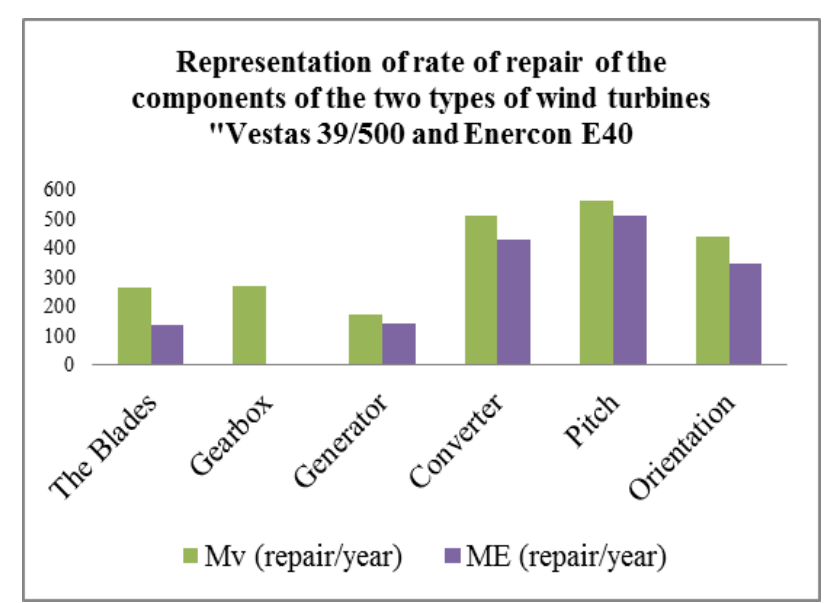

Fig. 5. Representation of rate of repair of components of Vestas39/500 and EnerconE40

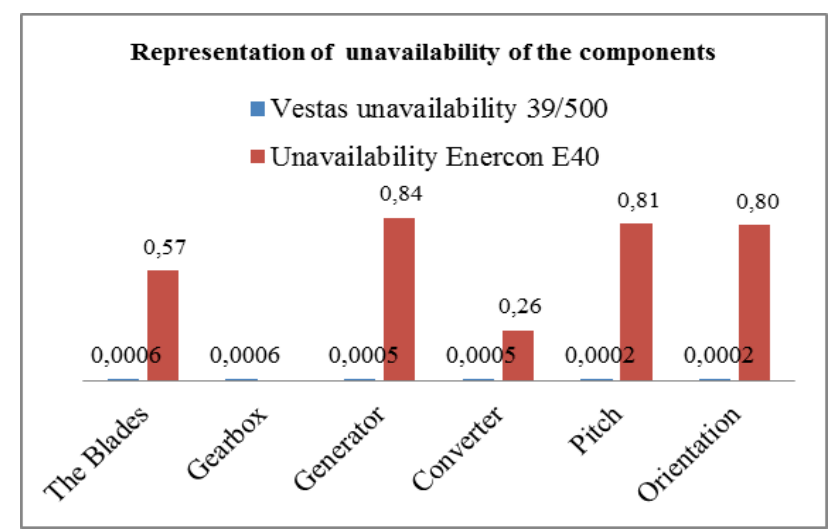

Fig. 6. The unavailability of components of Vestas 39/500 and Enercon E40

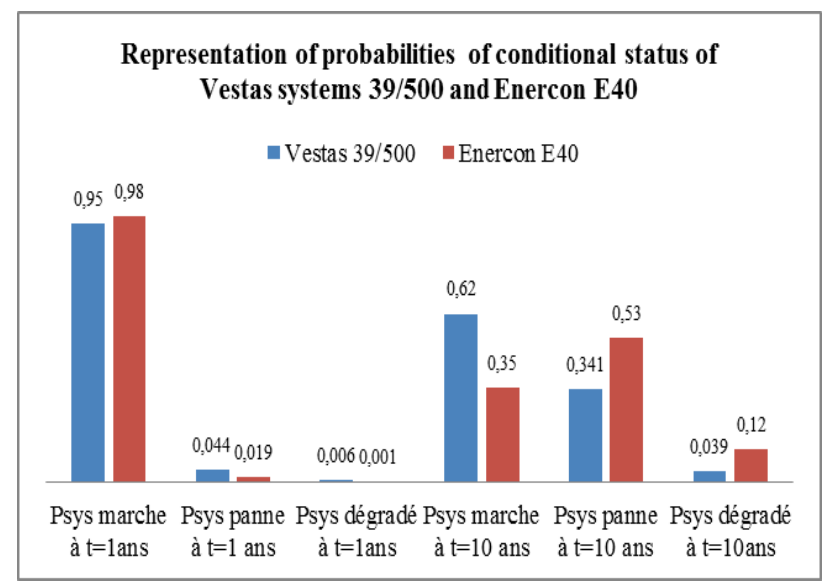

Fig. 7. The probabilities of conditional status of systems considered

According to the (Figures 4 and 5 and 6), the components of the wind turbine Enercon E40 are the most subject to failures that the components of the Vestas wind turbine $39 / 500$, as well as the components of the system Enercon E40 is less available than the system Vestas 39/500 (Figure 6).

It adds as well as the availability of the Vestas system $39 / 500$ is best through time than that of Enercon E40 (Figure 9), despite the fact that it has more components, and this is explained by the unavailability of remarkable the generator (Figure 6).

\section{Conclusion}

We have presented in this work a modeling by Bayesian networks of two wind turbines systems, the first to direct drive and the second is to indirect drive, in the aim to help the designer to make the choice between these two concepts and to determine the anomalies of each concept to improve them in the design phase.

As a conclusion of our work, the modeling has allowed us to determine the states of the system and the scenarios of operation in order to calculate the probabilities of States conditional of the system in dependence of the components and of the time. Of this fact, the results of the study showed us that the wind turbine system to indirect drive is no longer available as a system to direct drive and it is the most suitable for a choice based on availability.

As the prospect of work, it is to qualify this choice while taking into account other criteria of choice and to suggest improvements for the optimization of the other system to direct drive.

This is an Open Access article distributed under the terms of the Creative Commons Attribution Licence

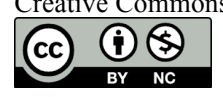




\section{References}

[1] E. Castillo, J. M. Gutiérrez, et A. S. Hadi, « Sensitivity analysis in discrete Bayesian networks », IEEE Trans. Syst. Man Cybern.Part Syst. Hum., vol. 27, no 4, p. 412-423, 1997.

[2] J. G. Torres-Toledano and L. E. Sucar, « Bayesian networks for reliability analysis of complex systems », in Ibero-American Conference on Artificial Intelligence, 1998, p. 195-206.

[3] D. Allen and A. Darwiche, « New advances in inference by recursive conditioning ", in Proceedings of the Nineteenth conference on Uncertainty in Artificial Intelligence, 2002, p. 2 10.

[4] P. Weber, G. Medina-Oliva, C. Simon, et B. Iung, « Overview on Bayesian networks applications for dependability, risk analysis and maintenance areas », Eng. Appl. Artif. Intell., vol. 25, no 4, p. $671-682,2012$.

[5] A. Bobbio, L. Portinale, M. Minichino, et E. Ciancamerla, « Improving the analysis of dependable systems by mapping fault trees into Bayesian networks ", Reliab. Eng. Syst. Saf., vol. 71, no 3, p. 249-260, 2001.

[6] A. Bobbio, E. Ciancamerla, G. Franceschinis, R. Gaeta, M. Minichino, et L. Portinale, " Sequential application of heterogeneous models for the safetyanalysis of a control system: a case study », Reliab. Eng. Syst. Saf., vol. 81, no 3, p. 269-280, 2003.

[7] H. Boudali and J. B. Duga, « A new Bayesian network approach to solve dynamic fault trees $»$, in Reliability and Maintainability Symposium, 2005. Proceedings. Annual, 2005, p. 451-456.

[8] H. Boudali and J. B. Dugan, « A continuous-time Bayesian network reliability modeling, and analysis framework », IEEE Trans. Reliab., vol. 55, no 1, p. 86-97, 2006.

[9] P. Weber, « Dynamic bayesian networks model to estimate process availability », in In 8th International Conference Quality, Reliability, Maintenance, CCF'02. Sinaia, Romania, 2002, p. 184-189.

[10] P. Weber and L. Jouffe, "Reliability modeling with dynamic bayesian networks ", in In 5th IFAC Symposium on Fault Detection, Supervision and Safety of Technical Processes (SAFEPROCESS'03), Washington, DC, USA, 2003, p. 57-62.

[11] P. Weber and L. Jouffe, « Complex system reliability modeling with dynamic object oriented Bayesian networks (DOOBN) ", Reliab. Eng. Syst. Saf., vol. 91, no 2, p. 149-162, 2006.

[12] S. Mahadevan, R. Zhang, and N. Smith, " Bayesian networks for system reliability reassessment », Struct. Saf., vol. 23, no 3, p. 231-251, 2001.

[13] M. Bensi, A. Der Kiureghian, and D. Straub, « Efficient Bayesian network modeling of systems », Reliab. Eng. Syst. Saf., vol. 112, p. $200-213,2013$.
[14] H. Langseth and L. Portinale, « Bayesian networks in reliability », Reliab. Eng. Syst. Saf., vol. 92, no 1, p. 92-108, 2007.

[15] H. Langseth and L. Portinale, "Applications of Bayesian Networks in Reliability Analysis "), in Bayesian Network Technologies: Applications and Graphical Models, IGI Global, 2007, p. 84-102.

[16] P. Weber and C. Simon, « Method of modeling by Bayesian Networks The reliability of a System Multi-states», in 11th International Congress multidisciplinary in quality, safety of operation and sustainable development, QUALITA 2015, 2015

[17] J. Pearl, «BAYESIAN NETWCRKS: A MODEL CF 'SELFACTIVATED MEMORY FOR EVIDENTIAL REASONING », 1985.

[18] K. Iqbal, X.-C. Yin, H.-W. Hao, Q. M. Ilyas, and H. Ali, « An overview of bayesian network applications in uncertain domains », Int. J. Comput. Theory Eng., vol. 7, no 6, p. 416, 2015.

[19] Z. CAI, P. GUO, S. LI, L. CONG, and Z. GENG, « Gallbladder Diagnosis and Importance Analysis based on Bayesian Network ", in Proceedings of the 23rd International Conference on Industrial Engineering and Engineering Management 2016: Theory and Application of Industrial Engineering, 2017, p. 269.

[20] P. Naïm, P.-H. Wuillemin, P. Leray, O. Pourret, et A. Becker, « Bayesian networks », Paris Eyrolles, 1999.

[21] D. Cram, M. May, R. Guelton, and S. Touch, « Abstract: Bayesian networks », 2005.

[22] B. Bouzy, « Bayesian networks », 2014.

[23] B. Multon, G. Robin, O. Gergaud, and H. B. Ahmed, « The electrical engineering in the wind: research in the area of the wind generation», in Congress young researchers in Electrical Engineering 2003, 2003, p. 10p.

[24] A. Boyette, « The control of a double fed asynchronous generator with storage system for the Wind Power Production», University Henri Poincaré-Nancy I, 2006.

[25] "Windstats ». [online]. Available on: Http://www.windstats.nl/. [Consulted The: 16-March-2017].

[26] "Startseite - Landwirtschaftskammer Schleswig-Holstein ». [online]. Available on: Http://www.lksh.de/startseite/. [Consulted The: 17-March-2017].

[27] Y. Feng, Y. Qiu, C. J. Crabtree, H. Long, et P. J. Tavner, « Monitoring wind turbine gearboxes », Wind Energy, vol. 16, no 5, p. 728-740, 2013.

[28] W. Yang, P. J. Tavner, C. J. Crabtree, Y. Feng, et Y. Qiu, « Wind turbine condition monitoring: technical and commercial challenges », Wind Energy, vol. 17, no 5, p. 673-693, 2014. 